\title{
A Economia da Caprinocultura em Pernambuco: Problemas e Perspectivas
}

\author{
Breno Sampaio ${ }^{1}$ \\ Yony Sampaio ${ }^{2}$ \\ Ricardo Chaves Lima ${ }^{3}$ \\ Amanda Aires ${ }^{4}$ \\ Gustavo Sampaio ${ }^{5}$
}

Resumo: A caprinocultura é uma das atividades mais indicadas para regiões semiáridas, sendo bastante explorada no nordeste brasileiro. São estimadas as produções de carne, leite e pele, o valor dessa produção e a participação no emprego em Pernambuco e analisados os mercados nacional e internacional. Enumeram-se os principais problemas para a expansão da cadeia, como manejo inadequado, problemas sanitários, limitações das instalações e das tecnologias. Com manejo melhorado, pode ser praticada por pequenos e médios produtores, sendo sustentável no semiárido, do ponto de vista ambiental, econômico e social, preservando a cobertura vegetal e mantendo a biodiversidade. O mercado de carne apresenta crescimento da demanda tanto nacional como internacional e déficit de oferta. $\mathrm{O}$ mercado de peles é outro mercado em expansão, com grandes perspectivas internas e para exportação.

Palavras-chave: Caprinocultura; Cadeia Produtiva.

\section{The Economics of Goat Production in Pernambuco: Problems and Perspectives}

Abstract: Goat production is one of the most adjusted activities to semi-arid zones. In Pernambuco, it is of great economic importance, as an alternative of

\footnotetext{
1 Departamento de Economia, Universidade de Illinois, UIUC. E-mail: brenosampaio@hotmail.com.

2 Professor Titular do Departamento de Economia, PIMES/UFPE, e Bolsista do CNPq. E-mail: sampyony@ yahoo.com.br.

3 Professor Adjunto do Departamento de Economia, PIMES/UFPE. E-mail: rlima@ufpe.br.

4 Mestranda em Economia, Departamento de Economia, PIMES/UFPE. E-email: amandaires@gmail.com.

5 Departamento de Economia, Universidade de Illinois, UIUC. E-mail: gsampaio@illinois.edu.
} 
supply for meat, skin, milk and sub-products. Meat, milk and pelt production and the total value of production and its participation in job generation are estimated. The national and international markets are analyzed. Several bottlenecks to an expansion of the supply chain are highlighted such as inadequate handling, sanitary problems, infrastructure and technology limitations. Under improved handling it is sustainable from an economic, social and environmental point of view for small and medium size producers. The market for meat is expanding, nationally and internationally. The market for pelts is also in expansion, again with good perspectives for the internal market and for exports.

Keywords: Goat Production; Supply Chain; Perspectives.

JEL: Q13, Q18, O13

\section{Introdução}

A caprinocultura, atividade presente em quase todos os países, é citada, frequentemente, como das atividades mais indicadas para a região semi-árida. Para tal, são destacados alguns aspectos: (a) a irregularidade climática torna a atividade agrícola de alto risco, reforçando a vocação pecuária, determinada desde o processo inicial de ocupação da porção semiárida do Nordeste, a partir de meados do século XVII; (b) a predominância da caprino ou ovinocultura em outras regiões semiáridas, como Espanha, Grécia, Austrália, por exemplo; (c) a adequação dessa atividade à pequena produção e à produção familiar devido à menor necessidade de capital para implantação e manutenção da caprinocultura, em relação à bovinocultura; e (d) a existência de mercado local e regional, devido ao consumo generalizado, no interior, da carne de ovinos e caprinos. Não obstante esta crença, há aspectos limitantes. A irregularidade climática também afeta negativamente a pecuária. No passado, quando da ocorrência de uma grande seca, as perdas do rebanho podiam chegar a quase $100 \%$, por falta d'água e de alimento. No geral, nos meses mais secos, há perda de peso, eliminando o ganho obtido nos meses de chuva e pasto farto. Com isto a produtividade é baixa. Os caprinos são mais recomendados para caatinga arbustiva e arbórea, mas respondem pouco, em ganho de produtividade, à melhoria das pastagens. Ao contrário dos caprinos, os ovinos adaptam-se mais a pastos herbáceos, mas nos meses mais secos, com sobrepastoreio, tornam-se agentes de grande degradação ambiental, pela forma intensa de aproveitamento do pasto. Nesse sentido, respondem bem à melhoria dos pastos, mas não são recomendados para áreas de caatinga mais arbustiva e arbórea.

A caprinocultura adentra o interior com as primeiras levas de colonizadores, com a expansão dos currais, que gera o chamado ciclo do couro, do gado. Por gado, entende-se tanto o criatório de grandes animais - bovinos e equinos como o de pequenos animais - caprinos, ovinos e porcos. Mas a criação de caprinos, por muitos anos, teve finalidade quase exclusiva de autoabasteci- 
mento. A menor quantidade de carne, quando do abate, adequava-se melhor à população rarefeita das antigas fazendas. $\mathrm{O}$ couro tinha aproveitamento local. O leite muito raramente era utilizado. A atividade econômica, entendida como geradora de renda, era a pecuária bovina, os rebanhos do interior sendo transportados para os centros urbanos de abate e consumo. A carne caprina era consumida localmente e teve importante papel como fonte proteica. Mas, na segunda metade do século XIX, há importante desenvolvimento do mercado de couros para exportação, constituindo o chamado mercado de courinhos. Ao final do século XIX, Delmiro Gouveia estabelece grandes negócios com importadores estrangeiros tendo importantes contatos em Nova Iorque, maior mercado comprador. Com a primeira guerra mundial o preço dos couros sofre extraordinária alta e Alagoas, que no ano 1903/1904 exportara apenas 3.278 peles, passa para 665.446 no ano seguinte, e 1.152.846 em 1915/1916. $\mathrm{O}$ ano seguinte marca o trágico fim de Delmiro e a dispersão do comércio de courinhos. Este importante capítulo para a caprinocultura se encerra. A caprinocultura retorna a seu caráter de quase subsistência.

A criação de caprinos visa a obtenção de três produtos principais: a carne, que destaca-se como o mais importante, dado o seu uso corrente pelo sertanejo, tanto para alimentação própria como para comercialização; o leite, de pouca expressão comercial; e o couro. Os couros tiveram participação importante como fonte de renda, no passado e, atualmente, continuam a ser exportados, sendo fonte de divisas. O abate mundial de caprinos, no período de 1991 a 2000, cresceu 7,5 \%. Em 1970, foram abatidos no Brasil 752 mil unidades caprinas e em 1992 esses números elevaram-se para 1.639 mil cabeças, representando um crescimento da ordem de 45,9\%.

Ao lado desse criatório comercial, há o mercado de genética, assim denominado pois visa a produção de reprodutores e matrizes. Este mercado envolve número bem menor de produtores, mas com marcante presença nas Associações de Criadores e nas Exposições de animais.

Há grande carência de estatísticas em relação à caprinocultura. Não existem estudos recentes que aportem dados primários às poucas estatísticas secundárias divulgadas pelo IBGE. Dada esta enorme carência, esforço é feito no sentido de suprir as deficiências com estimativas, feitas por extrapolação, quanto à produção e ao valor dessa produção. Devem ser tomadas como uma primeira estimativa, na ausência de dados mais precisos. De qualquer forma, configura um esforço pioneiro de estimação.

Após esta breve introdução, a seção seguinte apresenta a metodologia e a terceira descreve a caprinocultura em Pernambuco. Na quarta seção faz-se análise da economia da caprinocultura: são analisadas as produções de carne, leite e pele e são calculadas as participações no valor bruto da produção e no emprego em Pernambuco. Na quinta seção é feita análise do mercado de carne, leite e pele nacional e internacional. Na sexta seção são descritas perspectivas para o crescimento da cadeia. Por fim, na última seção são elaboradas as conclusões e recomendações. Embora o estudo de caso refira-se 
a Pernambuco, os autores pretendem que as conclusões e recomendações sejam válidas para a caprinocultura brasileira de um modo geral, devido à concentração da produção brasileira no Nordeste (mais de 92\%) e a do Nordeste nos estados da Bahia e de Pernambuco (60\%).

\section{Metodologia}

O trabalho adota a metodologia de análise de cadeias produtivas destacando os agentes, as instituições e as interações desenvolvidas com o objetivo de identificar problemas e potencialidades tecnológicas e organizacionais que viabilizem uma melhoria dessa atividade, ligada em boa medida à agricultura familiar (SEBRAE/NA 2000).

O trabalho é marcadamente multidisciplinar ao envolver aspectos econômicos, sociais e administrativos e técnicos da zootecnia. Esta visão multidisciplinar corresponde à compreensão ampla das cadeias produtivas, vistas em seu conjunto e sua funcionalidade e não segmentada por elos ou disciplinas.

Dada a carência de dados foram utilizados modelos matemáticos simples para estimação da produção de carne, leite e peles, a partir dos dados originais que se referem a rebanho. Foram utilizados coeficientes técnicos fornecidos em trabalhos especializados e obtidos em consulta com especialistas.

As estimativas de impactos indiretos foram feitas tomando por base matriz de insumo-produto elaborada para o Nordeste pelo Banco do Nordeste (BNB 2001). O setor agropecuário foi desdobrado, tomando-se a atividade "ovinocaprinocultura”.

A parte mais detalhada, referente a problemas técnicos e organizacionais, foi elaborada com base em consultas a técnicos e especialistas, sendo validada em seminário com produtores e técnicos de organizações privadas e do setor público.

\section{A Caprinocultura em Pernambuco}

Segundo a FAOSTAT, o Brasil representou, para o ano de 2004, 1,16\% da criação de caprinos no mundo e detinha o décimo segundo maior rebanho, possuindo apenas 9,05 milhões de cabeças, apesar das condições bastante favoráveis que se mostram iguais ou até superiores às dos maiores criadores.

A distribuição do rebanho brasileiro mostra-se bastante desigual entre as regiões. Para a região Nordeste, que representa menos de $20 \%$ da área territorial brasileira, há concentração, em 2006, de 9,61 milhões de cabeças, 
que representam 92,4\% do rebanho efetivo. Esse fato é explicado pela capacidade de adaptação do caprino às condições ecológicas do semiárido nordestino e às características edafoclimáticas e vegetativas, propiciando condições para o desenvolvimento da espécie.

No Brasil, há predominância dos pequenos criadores, definidos pelo tamanho do estabelecimento: aqueles com menos de 100 hectares. A distribuição do rebanho brasileiro em grupos de área total permite observar que o maior percentual do rebanho (91,7 \%) situa-se em áreas de menos de 10 ha. $\mathrm{Na}$ medida em que se aumentam as áreas, o percentual do rebanho diminui bastante, sendo para áreas maiores que 1.000 ha, de, aproximadamente, $0,2 \%$.

A distribuição dos produtores e do rebanho em Pernambuco (Tabela 1) comporta-se de forma semelhante à distribuição brasileira. No grupo de menos de 10 hectares estão situados $58,1 \%$ dos caprinocultores. Entre 10 e 100 hectares, encontram-se outros $34,8 \%$. Ou seja, $92,9 \%$ dos caprinocultores estão localizados em estabelecimentos com menos de 100 hectares. Nas condições do semiárido, esta é área considerada pequena, não permitindo obter uma renda superior a dois salários mínimos per capita (Helfand 2004). A distribuição do rebanho é algo distinta: ainda assim, $70 \%$ do rebanho é criado em estabelecimentos com menos de 100 hectares. Esta diversidade reflete a presença de pequenas explorações, com pequenos rebanhos, e áreas maiores, mas que ainda assim, nas condições típicas do semiárido, representam explorações familiares. Estas propriedades maiores, quase certamente, combinam a bovinocultura de carne com a caprinocultura. Os rebanhos médios, por grupo de área, variam de 8 cabeças apenas, em estabelecimentos com menos de 10 hectares, a 25 cabeças, nos estabelecimentos com 10 a menos de 100 ha, a 75 cabeças nos com mais de 100 a menos de 1000 ha; o rebanho médio apresenta apenas ligeiro crescimento entre 1996 e 2006, de 19 para 22 cabeças. Em todos, os rebanhos são diminutos. Mesmo nos poucos estabelecimentos com 1.000 a menos de 10.000 ha, o rebanho médio chega a apenas 223 cabeças. Rebanhos dessa dimensão, com manejo adequado, podem ser criados em áreas de até 30 hectares. O pequeno tamanho do rebanho, em relação à área, diz bem da criação extensiva, geralmente praticada com manejo bastante inadequado, principalmente no que se refere à alimentação e profilaxia. 
TABELA 1- NÚMERO DE PRODUTORES E EFETIVO DO REBANHO POR GRUPO DE ÁREA TOTAL - PERNAMBUCO, 1995-96 E 2006

\begin{tabular}{cccccc}
\hline $\begin{array}{c}\text { Grupos de Área } \\
\text { Total (ha) }\end{array}$ & \multicolumn{2}{c}{ Número de Produtores } & \multicolumn{2}{c}{ Efetivo do Rebanho } & $\begin{array}{c}\text { Rebanho } \\
\text { Médio }\end{array}$ \\
\hline Número & $\%$ & Número & $\%$ & \\
\hline Menos de 10 & 29.432 & 58,1 & 231.038 & 24,1 & 7,85 \\
$10<100$ & 17.601 & 34,8 & 437.330 & 45,5 & 24,85 \\
$100<1.000$ & 3.398 & 6,7 & 254.037 & 26,4 & 74,76 \\
$1.000<10.000$ & 167 & 0,3 & 37.205 & 3,9 & 222,78 \\
10.000 e mais & 1 & 0,0 & 300 & 0,0 & 300,00 \\
Sem declaração & 41 & 0,1 & 657 & 0,1 & 16,02 \\
Total em 1996 & 50.640 & - & 960.567 & - & 18,97 \\
Total em 2006 & 47.639 & - & 1.036 .449 & - & 21,76 \\
\hline
\end{tabular}

Fonte: IBGE, 1996 e 2007.

TABELA 2- EFETIVO DO REBANHO PERNAMBUCANO POR CONDIÇÃO DO PRODUTOR, 1995-96 E 2006

\begin{tabular}{cccccc}
\hline Condição do Produtor & \multicolumn{2}{c}{ Efetivo do Rebanho } & \multicolumn{2}{c}{ Número de Produtores } & $\begin{array}{c}\text { Rebanho } \\
\text { Médio }\end{array}$ \\
& Número & $\%$ & Número & $\%$ & \\
\hline Total em 2006 & 1.036 .449 & - & 47.639 & - & 21,76 \\
Total em 1996 & 960.567 & - & 50.640 & - & 18,97 \\
Proprietário & 807.533 & 84,07 & 38.920 & 76,85 & 20,75 \\
Arrendatário & 5.791 & 0,60 & 708 & 1,40 & 8,18 \\
Parceiro & 16.132 & 1,68 & 1.477 & 2,92 & 10,92 \\
Ocupante & 131.111 & 13,65 & 9.535 & 18,83 & 13,75 \\
\hline
\end{tabular}

Fonte: IBGE, 1996 e 2007.

Para a condição do produtor, seja proprietário, arrendatário, parceiro ou ocupante, apresenta-se a distribuição do rebanho pernambucano na Tabela 2. Cerca de 84\% dos produtores são proprietários; outros 13,6\% são ocupantes. Parceiros e arrendatários tem pouquíssima expressão. Em relação ao tamanho do rebanho, observa-se a predominância dos proprietários, que detém $77 \%$ do rebanho, seguido de ocupantes, parceiros e arrendatários. Os ocupantes, de modo geral, encontram-se estabelecidos em terras públicas, nas quais tem o efetivo domínio, mas não a propriedade, dependendo de regularização das áreas. No passado, a parceria teve expressão maior, mas mudanças nas relações de produção, ocorridas durante a segunda metade do século passado, tornaram-na inexpressiva.

Para os Estados localizados na região nordestina, destacam-se como maiores rebanhos, em 2006, o da Bahia, que concentra 42,1\% do rebanho total, o de Pernambuco, com 17,5\%, e o do Piauí, com 14,3\%. Os menores rebanhos são 
os do Rio Grande do Norte, com 4,2\%, do Maranhão, com 4,2\%, de Alagoas, com $0,7 \%$, e de Sergipe, com $0,2 \%$.

O Mapa 1 ilustra as microrregiões com participação de até 0,5\% sobre o valor total da produção, em reais (IBGE 1996). Destaca-se com a maior participação a microrregião geográfica do Juazeiro, representando percentual de 8,81\% sobre o total. Segue-se a microrregião de Euclides da Cunha, representando 6,54\%. A microrregião do Sertão do Moxotó, localizada em Pernambuco, detém a terceira maior participação, $3,86 \%$ do valor total.

\section{MAPA 1 - MAPA DO VALOR DA PRODUÇÃO DAS MICRORREGIÕES (R\$)}

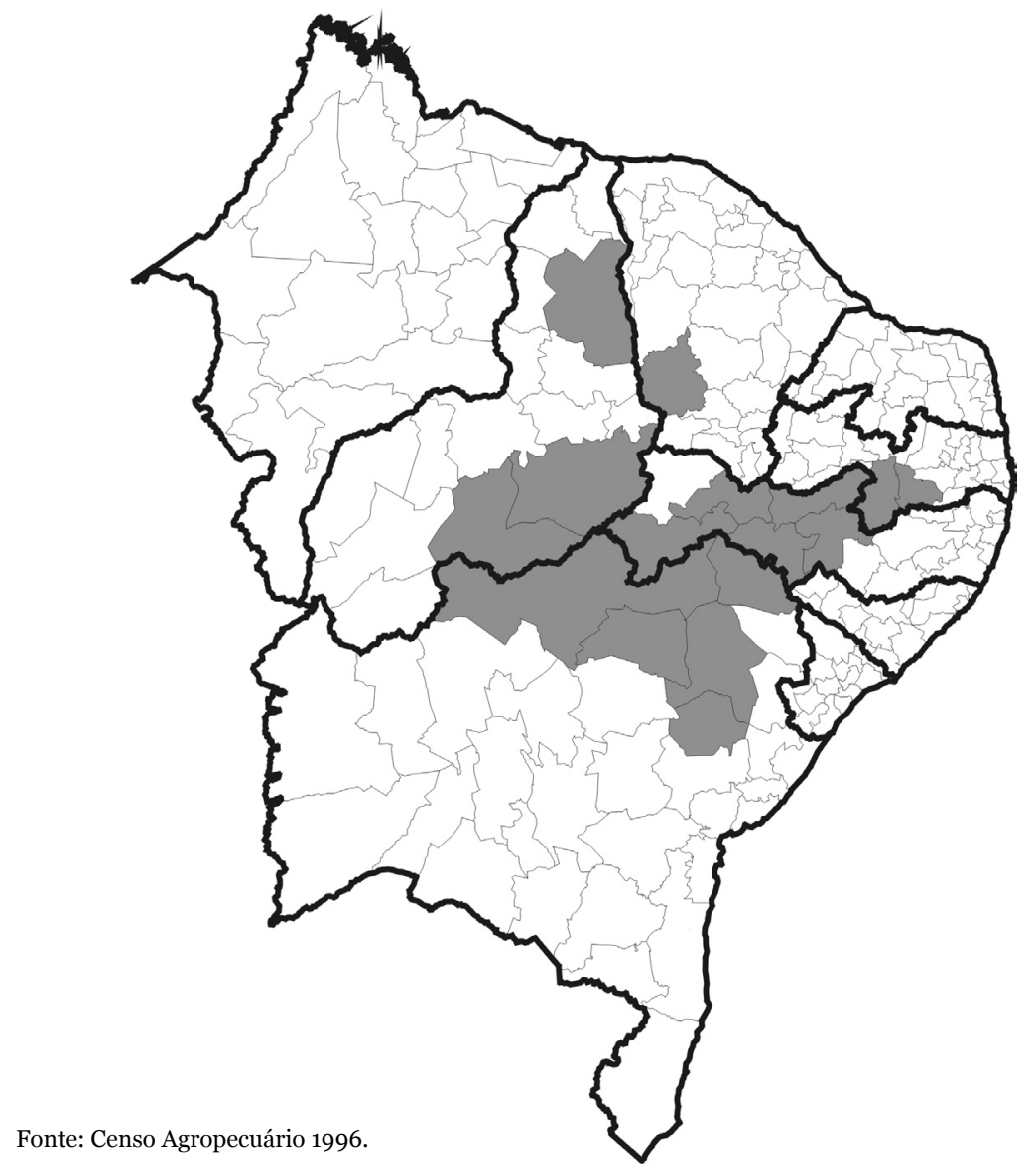


Em relação ao rebanho Pernambucano, nota-se que há elevada concentração na região do Sertão, que detém 89,73\%, leve presença na região do Agreste, com 8,50\%, e restando para a região litorânea, apenas 1,77\%. Esta distribuição confirma a maior potencialidade da caprinocultura no sertão semiárido. Mas há excelentes explorações de caprinos de raça no Agreste. Encontram-se criatórios de Boer P.O. em Pombos, Gravatá, Bezerros, Pesqueira, mas também em Arcoverde e Sertânia. Estes rebanhos compõem o chamado mercado de genética, voltado para a produção de reprodutores e matrizes. Mas, de modo geral, predominam mestiços, chamado de $\mathrm{SRD}$, sem raça definida. As três principais microrregiões, que concentram quase dois terços do rebanho estadual, são as de Itaparica, Petrolina e Sertão do Moxotó.

A atividade da caprinocultura é de extrema importância para a economia de Pernambuco, pois se apresenta como alternativa na oferta de carne, pele, leite e seus derivados. Este fato, além de contribuir para que ocorra melhoria na dieta alimentar da população, em grande parte rural, contribui também para um aumento significativo da renda do produtor e, por consequência, de sua qualidade de vida. Destaca-se igualmente a predominância da pequena produção familiar.

A Tabela 3 destaca alguns dos municípios que detém os maiores rebanhos do Estado. O município de Floresta, situado na microrregião de Itaparica, sobressai-se com o maior rebanho, com efetivo de 230.000 cabeças e representando 13,6\% do rebanho pernambucano total. Junto com Carnaubeira da Penha, antigo distrito de Floresta, representam mais de 18,4 \% do rebanho estadual.

TABELA 3 - MUNICÍPIOS PERNAMBUCANOS COM MAIOR REBANHO

\begin{tabular}{lcc}
\hline \multicolumn{1}{c}{ Município } & Rebanho & \% em PE \\
\hline Floresta & 230.000 & 13,6 \\
Sertânia & 100.000 & 5,9 \\
Petrolina & 80.500 & 4,8 \\
Carnaubeira da Penha & 80.100 & 4,8 \\
Parnamirim & 78.300 & 4,6 \\
Betânia & 65.000 & 3,8 \\
Ibimirim & 60.000 & 3,6 \\
Serra Talhada & 54.000 & 3,2 \\
Santa Maria da Boa Vista & 50.190 & 3,0 \\
Tacaratu & 49.500 & 2,9 \\
\hline
\end{tabular}

Fonte: PPM 2006 


\section{A Economia da Caprinocultura}

\subsection{Produção de Carne}

Não existe série para a produção de carne de caprinos no Brasil. Para a construção de uma tal série, foram utilizados parâmetros obtidos em estudo realizado pelo Banco do Nordeste (BNB 1999). Apesar de defasados, são os únicos dados existentes. Conversa com produtores mostra, no entanto, não ter ocorrido maiores mudanças. Foi obtida taxa de desfrute de $20 \%$ do rebanho ao ano. Os animais abatidos, com idade entre 8 e 10 meses, constatados como os preferidos para consumo, apresentam média de peso da carcaça entre 10 e 12 kg / animal (Nogueira Filho \& Kasprzykowski 2006). Portanto, para obtenção da série foi considerado um peso médio de $11 \mathrm{~kg}$ / animal. Os valores para produção de carne em Pernambuco obtidos encontram-se na Tabela 4.

O maior crescimento percentual anual ocorreu no período de 1999 a 2000, sendo de $19,45 \%$, e representando aumento na produção de carne de 503.589 $\mathrm{kg}$. Porém, mesmo registrando taxas crescentes, a produtividade de caprinos de corte em Pernambuco ainda é relativamente baixa. Este fato justifica-se pelo regime de manejo da exploração, que é predominantemente extensivo, com alta dependência da vegetação nativa, utilização de raças não especializadas, uso de práticas rudimentares de manejo, assistência técnica deficitária e baixo nível de organização e de gestão da unidade produtiva.

\subsection{Produção de Leite}

O leite de cabra apresenta bastante riqueza nutricional perdendo apenas para o leite humano e o leite da égua. É de excelente digestibilidade, rico em vitamina $\mathrm{D}$, cálcio e fósforo, sendo recomendado por vários profissionais da área de saúde. Além do leite, vários derivados são produzidos, como queijo, leite em pó, ricota, iogurte, doce, picolé, sorvete, pão de leite, sendo até utilizado na indústria de cosméticos.

Da mesma forma que para carne, a quantificação da produção de leite de caprinos esbarra no mesmo problema da escassez de dados. Portanto, de maneira semelhante, uma série de dados teve de ser construída. Segundo estimativas do IBGE (1999), o Brasil produziu 6,1 milhões de litros que, divididos pelo rebanho brasileiro de caprinos para o mesmo ano, resulta numa produção média de 0,7074 litros / cabeça. Com este valor, pôde-se estimar, através do rebanho, a produção de leite anual (Tabela 4).

Pode-se inferir que a produção de leite do estado vem apresentando crescimento. Este crescimento não é somente atual. Segundo a FAO (1993), o Brasil, no período compreendido entre os anos de 1980 e 1992, sobressaiu-se em crescimento em relação a todas as demais regiões produtoras, principal- 
mente em relação aos países mais desenvolvidos. Neste período, registrou-se incremento na produção de leite de 51,6 \% enquanto que a América Latina apresentou crescimento de $21,9 \%$.

\subsection{Produção de Peles}

A exportação de peles caprina acumulada para o Brasil no período de 1992 a 1999 foi de US\$ 25,9 milhões. Somente para o ano de 2000, chegou a representar US\$ 0,3 milhões, sendo os principais países importadores a Argentina, a Nigéria e a Itália.

O valor da produção de peles de caprinos de aceitação nacional e internacional, segundo Leite (2000), tem de modo geral correspondido a cerca de $20 \%$ do valor atribuído ao animal abatido, constituindo receita para o criador e gerando divisas para os estados e para o País. Para Jacinto (2001), diferentemente de Leite (2000), o valor da pele tem representado um ganho adicional para o produtor de 7,3 a 8,7\% em relação ao preço de venda da carcaça. Isto representaria, para animais vivos que tem peso entre 20 e $24 \mathrm{~kg}$ e que resultam com peso de carcaça entre 10 e 12 kg (Ribeiro \& Ribeiro 1998; Medeiros 1999), um ganho médio de $\mathrm{R} \$ 6,00$ por carcaça. Este valor excede o preço médio em 2007 da pele crua, que é cerca de R \$ 4,00. Porém, o preço já atingiu o patamar de $\mathrm{R} \$ 10$,oo quando o real esteve mais desvalorizado e as exportações foram expandidas. Este valor de $\mathrm{R} \$ 6,00$, calculado por Jacinto (2001), que corresponde em média a $8 \%$ do valor de venda da carcaça, tem representação bastante expressiva, podendo significar a diferença entre prejuízo e lucro da caprinocultura de corte.

A produção de peles em Pernambuco foi estimada da seguinte forma. Como dito acima, foi utilizada taxa de desfrute de $20 \%$ do rebanho ao ano, sendo estimado um abate, para o ano de 2003, de aproximadamente 302.381 animais. Para os animais abatidos, tomou-se estatísticas do Banco do Nordeste que situam o peso médio da pele entre 0,580 e 0,590 kg (BNB 1964). Portanto, para estimação da série, apresentada na Tabela 4, foi considerado o peso de $0,585 \mathrm{~kg}$ por pele. 
TABELA 4 - PRODUÇÃO DE CARNE, LEITE E PELES EM PERNAMBUCO

\begin{tabular}{cccc}
\hline Ano & Carne (Kg) & Leite (I) & Peles (Kg) \\
\hline 1999 & 2.588 .465 & 832.328 & 137.659 \\
2000 & 3.092 .054 & 994.258 & 164.441 \\
2001 & 3.175 .914 & 1.021 .223 & 168.901 \\
2002 & 3.269 .871 & 1.051 .436 & 173.839 \\
2003 & 3.326 .193 & 1.069 .546 & 176.893 \\
2004 & 3.372 .890 & 1.084 .538 & 179.376 \\
2005 & 3.523 .348 & 1.132 .917 & 187.378 \\
2006 & 3.708 .859 & 1.192 .567 & 197.244 \\
\hline
\end{tabular}

Fonte: Elaboração Própria.

\subsection{Participação do Valor Bruto da Produção em Pernambuco}

A participação da caprinocultura no valor bruto da produção pode ser estimada através da soma do valor da produção de carne, de leite e de peles. $\mathrm{O}$ valor da produção de carne e de leite foi calculado multiplicando-se a produção, apresentada na Tabela 4, pelo preço médio pago pelo consumidor. Para o cálculo do valor da produção de peles, considerou-se a quantidade de animais abatidos, sendo este valor multiplicado pelo valor pago por pele de cada animal abatido. O preço médio considerado para carne foi de 5,00 reais por quilo de carcaça, para leite foi de 1,15 real por litro e para pele de 4,00 reais por animal abatido (preços de junho de 2007). Os valores estimados da produção de carne, leite e peles são apresentados na Tabela 5. Com estes valores, a pele representa cerca de $6 \%$ do valor da carne.

TABELA 5 - VALOR EM REAIS DA PRODUÇÃO DE CARNE, LEITE E PELES EM PERNAMBUCO (reais de junho de 2007)

\begin{tabular}{ccccc}
\hline Ano & Carne & Leite & Peles & Total \\
\hline 2003 & 16.630 .966 & 1.229 .978 & 1.209 .524 & 19.070 .468 \\
2006 & 18.544 .295 & 1.371 .452 & 1.348 .676 & 21.264 .423 \\
\hline
\end{tabular}

Fonte: Elaboração própria.

Com base neste valor estimado para a produção da caprinocultura em Pernambuco, constata-se que a mesma não se situa entre as dez principais atividades da agropecuária (Tabela 6). Ou seja, tomadas indistintamente todas as principais atividades, a posição da caprinocultura é relativamente modesta. Mas, se for considerada que a cana-de-açúcar é concentrada na Zona da Mata e que a fruticultura irrigada está localizada predominantemente nas margens do São Francisco, ao passo que a bacia leiteira abrange o Agreste e pequenas porções da Zona da Mata, a caprinocultura situa-se, ao lado da 
bovinocultura de corte, como das principais atividades da porção semi-árida, não irrigada, do Estado. Também tem expressão no semiárido a produção de feijão e milho.

TABELA 6 - VALOR DA PRODUÇÃO AGROPECUÁRIA DE PERNAMBUCO 2003 (em reais de 2007)

\begin{tabular}{ccc}
\hline Produtos & Valor (100oR\$) & Participação (\%) \\
\hline Cana-de-açúcar & 615.631 & 26,77 \\
Bovinocultura de Carne & 295.277 & 12,84 \\
Avicultura & 198.492 & 8,63 \\
Leite Bovino & 178.902 & 7,78 \\
Uva & 162.358 & 7,06 \\
Mandioca & 109.550 & 4,76 \\
Banana & 108.678 & 4,73 \\
Manga & 98.952 & 4,30 \\
Tomate & 91.016 & 3,96 \\
Feijão & 70.795 & 3,08 \\
Goiaba & 42.622 & 1,85 \\
Cebola & 35.757 & 1,56 \\
Coco & 34.345 & 1,49 \\
Milho & 31.849 & 1,39 \\
Caprino & 19.070 & 0,83 \\
Suíno & 14.019 & 0,61 \\
Ovino & 13.389 & 0,58 \\
Total & 2.120 .702 & 100,00 \\
\hline
\end{tabular}

Fonte: IBGE, PAM e PPM, 2003.

\subsection{Participação no Emprego}

A caprinocultura é atividade complementar da agropecuária familiar. O trabalho é dividido entre diversos membros da família, sendo destacada a participação dos jovens e das mulheres no manejo dos caprinos. Em consequência, o trabalho é predominantemente familiar e complementar a outras atividades. Apenas nas poucas explorações maiores há emprego formal.

A literatura é bastante limitada quanto ao emprego gerado e não há estatísticas do emprego direto. Foi procedida estimativa com base em estudo que estabeleceu parâmetros de utilização de mão de obra (Pessoa 1972). Apesar de antiga, não ocorreram maiores mudanças no manejo que indiquem que estes parâmetros estejam superados. Por outro lado, são parâmetros correspondentes a módulos recomendados e não obtidos com base em dados coletados de produtores. Por ser a única estimativa encontrada na literatura, foi 
utilizado o parâmetro de um emprego para cada 5 hectares, correspondendo a um rebanho médio composto de um reprodutor e 40 matrizes. Esta lotação corresponde a um bom manejo, uma vez que na criação extensiva praticada usa-se como parâmetro uma lotação não agressiva ao meio ambiente de um animal por hectare. Extrapolando-se este parâmetro para o efetivo rebanho do estado, é obtido um total de 30.238 empregos.

Este emprego, como argumentado, não é formal nem é de tempo pleno, já que é reconhecida a pluriatividade. Mas é o somatório dos tempos de trabalho de uma força de trabalho maior porém só parcialmente ocupada.

O emprego indireto gerado pelas ligações para trás e para diante (forward and backward linkages), é limitado. A caprinocultura utiliza poucos insumos - vacinas, vermífugos e outros produtos veterinários - não ocorrendo, com frequência, aquisição de rações complementares. As ligações para diante decorrem do abate, preparo e venda da carne; do processamento e comercialização do leite e da confecção de queijo, atividades ainda limitadas, mas em expansão; e do preparo das peles, sendo que o acabamento final é geralmente feito fora do estado.

Com uso da matriz de insumo produto foi procedido cálculo do emprego indireto e induzido (Rodrigues \& Guilhoto 1998). Foi obtido um emprego total, não exclusivamente em Pernambuco, de 1.619 empregos. Somando o emprego direto e o indireto obtém-se um total de 31.857 empregos. Este emprego representa $3 \%$ do emprego total na agropecuária pernambucana.

\section{O Mercado Nacional e Internacional}

\subsection{Mercado de Carne}

A população brasileira vem superando antigas resistências ao consumo de carnes originárias de caprinos, porém, ainda existem fortes barreiras que dificultam maior conquista de mercado, como, por exemplo, o abate de animais velhos, não castrados e magros. Vale salientar que, diferentemente dos bovinos, os caprinos em geral não passam por processo de engorda (BNB 1999). Dessa maneira, acaba-se ofertando carnes de qualidade inferior, seja com relação à aparência, odor ou paladar.

O consumo potencial de carnes de caprinos pode ser estimado utilizando-se a POF (2003), dados referentes à aquisição alimentar domiciliar per capita anual. O valor atribuído ao consumo per capita para Pernambuco foi de 0,531 $\mathrm{kg}$ / ano e para o Brasil foi de $0,125 \mathrm{~kg} /$ ano. Sendo a população pernambucana da ordem de 8.161 .828 e a população brasileira de 174.632.932, o consumo potencial chega a ser de $4.333 .931 \mathrm{~kg}$ e $21.829 .117 \mathrm{~kg}$ para Pernambuco e Brasil, respectivamente. Esta é uma subestimativa do consumo, pois não leva em consideração o consumo não domiciliar, bastante expressivo no caso de 
caprinos. Comparando-se o consumo potencial com a oferta, conclui-se que para Pernambuco o consumo supera a oferta, que foi de $3.326 .193 \mathrm{~kg}$, em $1.007 .738 \mathrm{~kg}$. Para o Brasil, o consumo potencial também supera a oferta, que foi de $21.079 .636 \mathrm{~kg}$, em $749.481 \mathrm{~kg}$. Mas, como visto, o consumo estimado foi apenas o domiciliar. Todos estes números são estimados. Permitem, no entanto, constatar que Pernambuco é um importador potencial. Por outro lado, predomina o auto consumo da carne caprina. Boa parte da carne comercializada nas cidades e em restaurantes é de ovinos, segundo informações obtidas em revendedores e em restaurantes especializados. A razão principal decorre da carne caprina apresentar baixo rendimento, em relação à ovina, quando desossada.

O consumo da chamada carne de bode ocorre em restaurantes e bares especializados, tanto no interior como nas cidades maiores e capitais. A cozinha regional é especializada em bode assado, bode guisado, buchada e outros quitutes. Em restaurantes de cozinha internacional é raro se encontrar pratos com base na carne de caprinos; em geral há pratos com carne de carneiro. A carne de bode, mais magra, é muito mais saudável, porém ainda é motivo de certo preconceito.

Há lojas especializadas na comercialização da carne de caprino. Tanto para a classe média e alta, como boxes em mercados públicos que suprem a classe mais baixa. Nas lojas mais sofisticadas, a carne é apresentada em cortes especiais. São vendidas peças do chamado filé, na verdade cortes especiais em forma de tiras, o contra-filé, as costelas fatiadas, o carré, o pernil inteiro ou fatiado, a salsicha de bode. Para suprir essas lojas existem hoje pequenas empresas que abatem, cortam e embalam as peças. Destacase, no Nordeste, a Lanila Agropecuária localizada no Rio Grande do Norte (Lanila Agropecuária 2006). Nestas embalagens, a carne atinge preços bem mais elevados, podendo ser vendida acima de $\mathrm{R} \$ 10,00$ o quilo, enquanto a carne com osso é vendida em torno de $\mathrm{R} \$ 5$, oo o quilo.

\subsection{Mercado de Leite e Derivados}

Segundo estimativas do IBGE para o Brasil, para o período de 1996 a 1999, a oferta potencial de leite de cabra alcançou o valor de 6,1 milhões de litros anuais. Em contraposição, a demanda média potencial estimada (BNB 1999) foi de 12,0 milhões de litros anuais, resultando num déficit de 5,9 milhões de litros.

Não há estatísticas de consumo de leite de cabra, até por não existir mercado mais significativo para este produto. O consumo ocorre predominante nas áreas de produção. No entanto, em período mais recente, é possível encontrar nos supermercados, leite de cabra, inclusive longa vida. Em 2006, encontravase, nos principais supermercados, o leite Cappry’s, da região de Viamão, no 
Rio Grande do Sul, e o Caprilat, de Nova Friburgo, no Rio de Janeiro.

Na região, tem sido estimulada a produção de leite. Nos Estados da Paraíba, do Rio Grande do Norte e de Pernambuco, foram estabelecidos programas para compra e pasteurização do leite de cabra, sendo a venda efetuada no próprio local. Como consequência, a produção tem aumentado. Estima-se, para Pernambuco, uma produção de 2 mil litros dia, ou cerca de 730 mil litros ano. Dessa produção, cerca de 1.300 litros dia são comprados pelo Programa Fome Zero. O programa assegurava ao produtor, em 2006, um preço médio de 70 centavos por litro, e RS 1,15 ao laticínio. O leite é distribuído gratuitamente à famílias com baixa renda e com crianças menores.

São três os laticínios operando no estado de Pernambuco. O maior, o Dom Bosco, tem capacidade para processar 1.00o litros dia. Espera-se o ingresso de outros três laticínios. Operam com leite pasteurizado. O leite longa vida é produzido fora do estado, no Rio de Janeiro e no Rio Grande do Sul.

A produção de queijo de cabra ainda é muito limitada. Apesar da fama internacional do queijo de cabra, e do elevado preço que atinge na Europa - na Franca, na Itália, na Grécia, por exemplo - o seu sabor marcante ainda é pouco apreciado no Brasil. São pouquíssimos os produtores, sendo que alegam que o custo de produção é mais elevado e o preço de venda é alto para um mercado tão restrito. Ainda assim, encontram-se, em lojas mais sofisticadas, queijos de cabra produzidos no Agreste de Pernambuco. De muito se espera uma expansão desse mercado, abrindo perspectivas para a colocação de mais tipos e maior volume, mas o mercado permanece restrito.

\subsection{Mercado de Peles}

O mercado importador mundial classifica as peles caprinas em quatro categorias: A, B, C e D. Estas categorias baseiam-se em critérios como tamanho, peso e tipo de fibra (pêlo) e estabelece o uso para cada categoria (Holst 1990). Na categoria A, as peles devem ser pequenas, finas, leves com pelos curtos e finos e provenientes de caprinos jovens. As peles dessa categoria são de grande interesse e apresentam alto valor de mercado. Isso se deve à aparência estética do produto acabado, resultante da aparência de um grão, que por sua vez, provém do padrão criado pela disposição dos folículos pilosos na superfície do couro. Na categoria B, estão compreendidas as peles grandes, espessas, pesadas e com pêlos grosseiros. Esta categoria se encaixa mais para fabricação de bolsa e não existe grande demanda. A categoria $\mathrm{C}$, compreende as peles de qualidade intermediaria. Existe relativa demanda e é largamente utilizada no mercado de calçados. A categoria D compreende as peles com alta densidade de pêlos, com destaque para a raça angorá. Esta categoria está sujeita a flutuações de demanda, relacionadas diretamente a tendências da moda feminina. No Nordeste, utilizando classificação para o mercado interno, 
tem-se, em média, 4\% de primeira, 14\% de segunda, 26\% de terceira e 56\% de quarta categoria (BNB 1999).

Por tamanho, as peles são classificadas em pequenas, regulares e especiais. A distribuição, no Nordeste, é de 16\% de pequenas, 62\% de regulares e 22\% de especiais (BNB 1999).

A boa aparência das peles de caprinos relaciona-se com a alta densidade de folículos primários de diâmetros uniformes, menores que $60 \mu \mathrm{m}$, produtores de finas fibras meduladas. Esta boa aparência, diretamente relacionada com a qualidade da pele, decresce com a idade, pois o número de folículos primários é determinado desde o nascimento do animal e, com a idade, aumenta também a área da pele e, portanto, diminui a densidade folicular.

As peles de caprino no Nordeste apresentam inúmeros defeitos, decorrentes de riscos em cercas de arame, bernes, vacinas, esfola e má conservação. Estimase que $40 \%$ das peles são refugadas por inadequação aos padrões.

A produção de peles é direcionada para o mercado interno, com uma parcela menor sendo exportada. O mercado do centro-sul é o grande comprador. As peles finas de caprinos são utilizadas na confecção de calçados e bolsas, vestimentas e pastas.

As exportações brasileiras estão distribuídas em diversas categorias. Na Tabela 7 apresentam-se dados sobre a exportação de peles em período recente. A Bahia e o Ceará, maiores exportadores no passado, cedem lugar a Pernambuco, destaque no couro "wet blue", submetido a tratamento químico à base de cromo, e preferido pela indústria de calçados. A participação de Pernambuco limita-se a apenas três grupos: couros sem peles umid. "wet blue", outros couros sem peles , curtidos, e couros / peles no estado seco, "crust" (Tabela 8). Destes, apenas o tipo "wet blue" apresenta exportação mais regular, mas com grande queda em 2004.

TABELA 7 - EXPORTAÇÃO BRASILEIRA DE PELES (US\$ DÓLARES)

\begin{tabular}{cccc}
\hline Item & $\mathbf{2 0 0 2}$ & $\mathbf{2 0 0 3}$ & $\mathbf{2 0 0 4}$ \\
\hline Couros s/pele c. précurt. vegetal & 0 & 394 & 8566 \\
Couros s/peles umid. "wet blue" & 529.654 & 889.620 & 231.701 \\
Out. couros / peles, curtidos & 544.617 & 48.964 & 89.831 \\
Couros / peles no estado seco, "crust” & 43.951 & 0 & 15.479 \\
Couros curtidos no cromo & 467.516 & 121.329 & 143.863 \\
Outros couros prep. Após curtimento & 9.980 & 21.103 & 42.760 \\
\hline Total & 1.595 .718 & 1.081 .410 & 532.200 \\
\hline
\end{tabular}

Fonte: MDIC. Aliceweb, 2005. 
TABELA 8 - EXPORTAÇÕES PERNAMBUCANAS DE PELES

\begin{tabular}{cccc}
\hline Item & 2002 & 2003 & 2004 \\
\hline Couros / peles "wet blue" & 529.654 & Valor (US\$) \\
Outros couros / peles curtidos & 97.389 & 0 & 231.701 \\
Couros / peles, no estado seco “crust” & 0 & 0 & 0 \\
\hline Couros / peles "wet blue” & & Quantidade (kg) & \\
Outros couros / peles curtidos & 80.368 & 127.502 & 32.310 \\
Couros / peles, no estado seco "crust” & 7.550 & 0 & 0 \\
\hline
\end{tabular}

Fonte: MDIC.Aliceweb, 2005.

\section{Perspectivas}

O frágil ambiente do semiárido apresenta severas limitações de clima - baixos índices pluviométricos e acentuada irregularidade ao longo do ano e entre anos - e de solo que restringem o seu uso na agropecuária. A sua utilização inadequada, com retirada da cobertura vegetal e exposição temporária do solo, tem propensões a acentuar processo de desertificação já em curso em algumas áreas. O sobrepastejo é uma das práticas condenadas. A caprinocultura é das poucas atividades que se prestam adequadamente ao semiárido preservando a cobertura vegetal e mantendo a biodiversidade. Adicionalmente, a caprinocultura, com manejo melhorado, pode ser praticada por pequenos e médios produtores. Torna-se uma das poucas atividades sustentáveis no semiárido, do ponto de vista ambiental, econômico e social. Mas, para tal, deve-se observar práticas recomendadas de manejo reprodutivo, manejo alimentar e manejo profilático. O rebaixamento e raleamento da caatinga, com ou sem enriquecimento forrageiro, combinado com suplementação alimentar e adequada lotação para a área, é rentável e ecologicamente sustentável. O manejo reprodutivo que enseja aumento da parição e desmame em época correta, ao lado da suplementação alimentar na época do desmame e na entressafra e o manejo sanitário, com destaque para a vermifugação sistemática, elevam a produtividade e conferem rentabilidade. Por fim, a dimensão da propriedade é crucial para determinar renda mínima competitiva que justifique a permanência dos produtores na atividade. Essa dimensão precisa ser melhor estudada, mas estabelecimentos com menos de 20 hectares, no semiárido, seguramente não permitem gerar renda que dê sustentabilidade econômica a uma família.

Do lado da demanda as perspectivas são alvissareiras. A ampliação dos abatedouros e a prática de preparo de cortes especiais apresentam amplas perspectivas de colocação da carne no mercado interno e até para exportação. Pelas qualidades nutritivas e dado o crescimento da demanda por carnes, 
principalmente na Ásia, como consequência do crescimento da população e principalmente da elevação da renda (IFPRI 2005). Constata-se, no mercado interno, demanda potencial elevada e déficit de oferta para atender este mercado mais especializado, com preços mais remunerativos.

O mercado de peles é outro mercado em expansão, com grandes perspectivas tanto internas, devido ao Brasil vir-se constituindo em importante polo calçadista, inclusive com expansão no Nordeste, como para a exportação. Novamente, destaca-se a excelente qualidade das peles caprinas da região e a possibilidade de elevar o aproveitamento se diminuídos defeitos decorrentes de riscos em cercas de arame e esfolas. O controle da linfodernite ou mal de caroço é outro fator importante para melhoria das peles. Combinado com a expansão e a melhoria dos curtumes, parece melhorar as perspectivas para vendas de peles tipo "wet blue" e outras peles curtidas.

O mercado de leite e derivados ainda está por ser descoberto e pode se tornar o mais dinâmico. A produção de leite é muito pequena e o número de laticínios que processam leite de cabra no Estado é pequeno, embora esteja em expansão. Destaca-se novamente a qualidade do leite de cabra e seu uso por crianças que apresentam incompatibilidade com o leite bovino. Alem disso, e com perspectivas ainda mais promissoras, destaca-se a diversidade de produtos, de iogurtes e queijos, destes mais de 300 tipos, produzidos na Europa, e vendidos a preços elevados, que ainda não fazem parte da dieta nacional. A criação deste mercado, com ação combinada do Estado e de associações de produtores, abre perspectivas para sedimentar a atividade, além de enriquecer a cultura nacional. Lembra-se, a propósito, o estabelecimento de costumes, como o de consumo do queijo do reino, e a ampliação recente de saudável culinária japonesa, como exemplos de criação de demanda. O mesmo pode ocorrer em relação aos queijos de cabra e outros derivados.

O mercado da genética, após a classificação de médio risco obtida pelo Estado também apresenta boas perspectivas.

As perspectivas afiguram-se como excelentes, tanto do lado da oferta, com manejo adequado e ecologicamente correto, como do lado da demanda, interna e para exportação.

\section{Conclusões e Recomendações}

A análise dos problemas enfrentados pela cadeia de caprinos é de extrema importância, pois permite apontar rumos que venham a melhorar seu desempenho. As conclusões e recomendações obtidas foram subdivididas em quatro tópicos: (a) manejo e produção, (b) convivência com a caatinga, (c) instalações e (d) produção de carne, leite e derivados e peles. 
Quanto à (a) melhoria do manejo e da produção, seis fatores merecem destaque:

1) manejo reprodutivo: as taxas de natalidade e de mortalidade e o ganho de peso dependem fortemente do manejo reprodutivo com parição e desmame na época de maior oferta de pasto nativo. A adoção de manejo reprodutivo compatível com as condições da região requer capacitação dos produtores.

2) manejo alimentar: uma das maiores deficiências do manejo corrente decorre da falta de suplementação alimentar, principalmente na época seca. Como consequência, há queda do ganho de peso e da produtividade. $\mathrm{O}$ manejo alimentar adequado compreende igualmente a recuperação e preservação da caatinga e a combinação entre o manejo reprodutivo e o alimentar. Muitos pequenos produtores não se encontram sensibilizados para a necessidade de suplementação alimentar. Além de capacitação, pode ser necessário ofertar linha de crédito combinada.

3) manejo sanitário: a caprinocultura apresenta baixas taxas devido à ausência de vacinação e vermifugação sistemáticas. Outros controles são importantes, como o de ectoparasitas, mas grande destaque tem as verminoses, como uma das grandes causas da elevada mortalidade. A capacitação dos produtores e a demonstração de resultados é uma primeira ação para melhoria dos rebanhos e elevação da produtividade.

4) capacitação laboral, gerencial e técnica: por ser atividade tradicional no semiárido, a resistência a mudanças é arraigada. Para efetivar as mudanças necessárias, no manejo e na administração da produção, recomenda-se elaboração de programas de capacitação. Esses programas devem ter a participação dos envolvidos diretamente com a produção, os trabalhadores, os responsáveis pela parte técnica e os gerentes. Na agropecuária familiar estas três funções podem estar sendo exercidas por um único individuo. Assim, a capacitação deve envolver módulos técnicos e gerenciais, que capacitem os produtores para a tomada de decisão em função de características particulares do ambiente.

5) realização de campanhas periódicas de vacinação, vermifugação e mineralização do rebanho: a adoção de práticas recomendadas pode ser ajudada por campanhas mais gerais de vacinação, vermifugação e mineralização do rebanho. Estas campanhas têm efeito demonstração importante e servem adicionalmente para diminuir a possibilidade de comportamento não colaborativo, no caso de práticas que se assemelhem a bens públicos.

6) estímulo ao aumento da oferta alimentar, sobretudo no período seco, com ênfase nas seguintes tecnologias: (a) manejo da caatinga; (b) utilização de restolhos de cultura e subprodutos agroindustriais; (c) formação de bancos de proteínas e de campos forrageiros; (d) conservação de forragens (fenação, ensilagem, etc.). 


\section{Quanto à (b) melhoria da convivência com a caatinga, destacam-se dois fatores:}

1) manejo com rebaixamento e raleamento da caatinga: a caprinocultura com sobre pastejo pode ser detrimental ao meio ambiente frágil do semi-árido. Pode reforçar tendências à desertificação e diminuir a biodiversidade. No entanto, com adequado manejo da caatinga é possível tanto elevar a produtividade da pecuária como recuperar e preservar a caatinga. Campanhas maciças para adoção de práticas melhoradas são bem vindas pela sustentabilidade econômica, social e ambiental.

2) formação de pastagem complementar - palma e conservação de forragem: a formação de pastagem complementar, seja com plantio de palma forrageira ou adoção de ensilagem ou fenação, permite seja diminuída a pressão sobre a vegetação nativa no período da seca, ao mesmo tempo que evita perda de peso e eleva a produtividade do rebanho.

\section{Quanto à (c) a melhoria das instalações, destacam-se dois fa- tores:}

1) construção de instalações básicas: a caprinocultura exige instalações relativamente simples e baratas. Mas para manejo adequado é essencial uma área coberta, com divisões. Para melhor manejo sanitário deve ser construído brete simples. Mesmo em criatório extensivo, o rebanho deve ser recolhido, para inspeção e tratamentos, o que requer instalações básicas.

2) crédito com assistência técnica: a melhoria das instalações, mesmo que simples, requer investimentos. Pequenos e médios produtores geralmente não dispõem de recursos próprios para investimento. Programas de crédito tornam-se essenciais. No entanto, o crédito deve ser atrelado à assistência técnica e a capacitação para melhor efeito.

\section{Para (d) a melhoria da produção de carne, leite e derivados e peles, cinco fatores são importantes:}

1) qualidade das ordenhas, processamento e comercialização do leite (pasteurizado, longa vida, etc.): a higiene das ordenhas é condição sine qua non para melhoria da qualidade sanitária do leite. Adicionalmente, a limpeza dos vasilhames e outros cuidados sanitários tornam-se necessários. A pasteurização do leite de cabra já ocorre no Estado e outros laticínios estão em processo de instalação. No entanto, a comercialização é limitada, não havendo oferta regular nas cidades maiores. Embora a recomendação seja em favor da me- 
lhoria da sanidade e do consumo de leite pasteurizado, deve ser estudada a possibilidade de outros processamentos.

2) produção e comercialização de queijos de cabra: os queijos e outros derivados têm largo consumo em países mais desenvolvidos. Não existe este costume no Brasil, em particular no Nordeste. As poucas tentativas para produção de queijos finos tem se defrontado com mercado diminuto. Mas, à exemplo do que ocorreu com outros produtos, como os da culinária japonesa, é possível, através de campanhas e festivais, estimular e induzir o consumo. O Nordeste pode igualmente suprir parte do consumo do sudeste, substituindo em parte queijos importados.

3) preparo de peles: há grande potencialidade para melhoria das peles de caprinos, melhor processamento e suprimento à indústria calçadeira nacional e do exterior. A indústria de curtumes merece maiores estudos para indicação das necessidades. Este estudo deve contemplar análise detalhada das instalações disponíveis e das perspectivas de comercialização das peles, tanto no mercado interno como no exterior.

4) expansão de abatedouros pequenos e de médio porte, com preparação de cortes especiais: a maior parte do abate ainda é clandestino e a venda da carne se dá em feiras livres. É importante preservar este consumo local, importante para suprimento proteico das populações interioranas. Mas, por outro lado, há amplo mercado regional e nacional, para cortes especiais. Para isto, é necessária ampliação do número de abatedouros, regularização dos existentes e a instalação de equipamentos simples para corte e acondicionamento da carne.

5) pesquisa sobre sistemas de produção e sua rentabilidade econômica: a grande carência de estudos econômicos sobre a caprinocultura impede que sejam tiradas conclusões mais nítidas sobre diversas práticas recomendadas. Um dos poucos estudos conclui que algumas práticas importantes para melhor convivência com o semiárido podem não ser econômicas, do ponto de vista do produtor privado. Esta carência recomenda com urgência a realização de estudos mais conclusivos sobre práticas e sua economicidade. 


\section{Referências}

BANCO DO NORDESTE DO BRASIL (1964). A Indústria de Curtumes do Nordeste. Fortaleza, 279.

BANCO DO NORDESTE DO BRASIL (1982). Desempenho da Caprinocultura e Ovinocultura no Nordeste. Fortaleza, 47.

BANCO DO NORDESTE DO BRASIL (1999). Programa de Desenvolvimento da Ovinocaprinocultura do Nordeste. Arquivo PDF, 61.

BANCO DO NORDESTE DO BRASIL (2001). Macroeconomia do Nordeste - 19701998. Fortaleza.

FAO (2004). FAOSTAT. URL [On Line]: http://www.fao.org/faostat/index_en.asp. Acesso em: 2004.

HELFAND, S.M. (2004). "What can be learned from the agricultural censuses about rural poverty in Brazil.” Artigo não publicado.

HOLST, P.J. (1990). "Pretanning factors that affect the grain appearance on goat leather." Cowra: NSW Agriculture e Fisheries. Technical Bulletin 36: 1-5.

IBGE. Censo Agropecuário 1995-1996. URL: http://www.ibge.gov.br.

IBGE. Censo Agropecuário 2006. URL: http://www.ibge.gov.br.

IBGE. POF 2OO3. URL: http://www.ibge.gov.br.

IFPRI. (2005). "New Risks and Opportunities for Food Security - Scenarios Analyses for 2015 and 2050.” Policy Briefs 73. International Food Policy Research Institute, Washington.

JACINTO, M. (2001). “Alternativas de Aproveitamento de Pele Caprina e seu Impacto na Rentabilidade da Caprinocultura de Corte.” Artigo não publicado.

LANILA AGROPECUÁRIA (2006). URL [On Line]: http://www.lanila.com.br/ lanila/ index.html. Acesso em: agosto de 2006.

LEITE, E. (2000). “Ovinocaprinocultura no Nordeste: organização e crescimento.” URL [On Line]: http://www21.sede.embrapa.br/noticias/artigos/2000/ artigo.2004-12-07.2538681592/mostra_artigo. Acesso em: 2005.

MEDEIROS, A. (1999). “Caprinocultura de corte no Nordeste brasileiro.” URL [On Line]: http://www.capritec.com.br. Acesso em: 2005.

NOGUEIRA FILHO, A. \& KASPRZYKOWSKI, J. (2006). “O agronegócio da caprinoovinocultura no Nordeste brasileiro.” Documentos do ETENE. Banco do Nordeste, Fortaleza, 54 .

NOGUEIRA FILHO, A. \& ALVES, M.O. (2002). "Potencialidades da cadeia produtiva da ovinocaprinocultura na Região Nordeste do Brasil.” BN/ETENE.

PESSOA, A. (1972). “Criação de caprinos em pequenas e médias áreas.” BANDEPE, Recife, 156.

RIBEIRO, S. \& RIBEIRO, A. (1998). “Caprinocultura de corte.” URL [On Line]: http://www.capritec.com.br/art29.htm. Acesso em: 2005.

RODRIGUES, M. \& GUILHOTO, J. (1998). "Eficiência Alocativa do Fundo Constitu- 
cional de Financiamento do Nordeste (FNE) - uma visão de insumo produto.” Revista Econômica do Nordeste 29(3):319-48.

SAMPAIO, Y. \& VITAL, T. \& COSTA, E.F. (2003). "Expansão e Perspectivas do Agronegócio no Nordeste." Banco do Nordeste do Brasil, Fortaleza.

SEBRAE/NA (200o). "Metodologia do Programa SEBRAE: Cadeias Produtivas Agroindustriais.” Brasília, 56.

Submissão: 29 de fevereiro de 2008

Primeira resposta: 9 de julho de 2008

Aceite: 23 de janeiro de 2009 



\section{Últimos lançamentos}

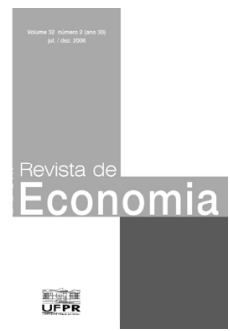

\section{v. 35, n. 1, jan./abr. 2009}

Análise econômico-financeira da implantação do sistema de biodigestores no Município de Toledo (PR)

D. Junges \& S. Kleinschmitt \& P. Shikida \& J. da Silva

Um estudo comparativo das disparidades salariais entre os migrantes nordestinos e os nativos paulistas no mercado de trabalho de São Paulo

R. Schmidt Filho \& P. do Monte \& M. Miceli

Plataforma logística: estudo da viabilidade de implantação em Juiz de Fora $(M G)$ via caracterização das mercadorias transportadas entre Minas Gerais e Rio de Janeiro

S. Bastos \& F. Perobelli \& M. Maciel \& T. dos Santos

Determinantes das variações na desigualdade dos rendimentos do mercado formal de trabalho na agricultura do Rio Grande do Sul V. Stülp \& I. Bagolin

Industrialização e substituição de importações no Brasil e na Argentina: uma análise histórica comparada

L. Mattei \& J. Santos Júnior

Efetividade de hedge do milho com contratos futuros da BM\&F: uma aplicação para a região de Maringá (PR)

J. M. Tonin \& M. J. Braga \& A. B. Coelho

\section{v. 34, n. 3, set./dez. 2008}

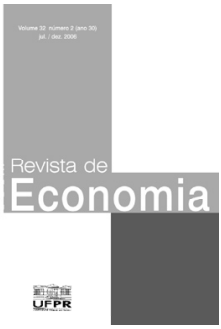

Promovendo exportações de móveis: aspectos da implementação do PROMÓVEL no aglomerado moveleiro de São Bento do Sul (SC)

Hoyêdo Nunes Lins \& Priscila Azevedo Guimarães

Análise espacial da criminalidade no Rio Grande do Sul

Cristiano Aguiar de Oliveira

O estado e a inserção ativa na economia: a estratégia de desenvolvimento econômico da China

Giuliano Contento de Oliveira

Sobre a política de combate à pobreza no governo Lula

Rosa Maria Marques \& Áquilas Mendes

Inovação em produtos agroalimentares: uma avaliação das mudanças qualitativas no suíno utilizando conjuntos fuzzy

Júlio Eduardo Rohenkohl \& Orlando Martinelli \& Rosângela Ballini

Racionalidade limitada e modelos mentais: aspectos cognitivos dos agentes econômicos na economia institucionalista

Ednilson Silva Felipe 



\section{Revista de Economia}

A Revista de Economia é editada pelo Departamento de Economia da UFPR desde 1960 e publica trabalhos inéditos na área de Economia e correlatas, prezando pelo caráter interdisciplinar das ciências sociais e humanas.

Seguindo a tradição pluralista do Departamento de Economia e do Programa de PósGraduação em Desenvolvimento Econômico, a Revista de Economia dá espaço a trabalhos de qualidade acadêmica independentemente de sua matriz teórica. Artigos e resenhas das mais diversas bases metodológicas em Economia e interligados a outras áreas das ciências sociais e humanas são bem-vindos e considerados pelo seu mérito acadêmico.

A Revista de Economia é indexada em bases bibliográficas nacionais (Perie, Funpec-RP) e internacionais (SSRN; Public Knowledge Project; Sysbibli)

\section{Normas para a submissão de trabalhos}

1. São aceitas submissões de artigos, comunicações e resenhas em português, espanhol ou inglês. O trabalho submetido deve ser inédito e não deve estar submetido a outras publicações. Casos de submissão simultânea serão divulgados pelos círculos profissionais.

2. Os trabalhos devem ser submetidos eletronicamente através do portal SER: http:// www.ser.ufpr.br/economia. Com a submissão do texto, os autores concordam que os direitos autorais de primeira publicação são da Revista de Economia. Os artigos são de uso gratuito, com atribuições próprias, em aplicações educacionais e não comerciais. A submissão do trabalho implica na autorização de sua publicação e de sua utilização por outros autores, desde que citada a fonte.

3. Os artigos devem ter:

3.1 até 7.500 palavras (incluindo título em português, título em inglês, resumo, abstract, rodapés, referências, tabelas e gráficos) em páginas de tamanho A4;

3.2 espaçamento simples em editores de texto compatíveis com o Word para Windows, parágrafos sem recuo, com espaçamento de 6 pontos, e margens de $3 \mathrm{~cm}$;

3.3 um resumo de até 150 palavras em português e outro em inglês, três palavraschave e correspondentes em inglês, e classificação por área segundo o Journal of Economics Literature;

3.4 referências bibliográficas completas em conformidade com o sistema de referências de Harvard; 
3.5 tabelas, gráficos e quadros sem cores, numerados em sequência, com títulos em letras maiúsculas, e devidamente mencionados no corpo do texto.

4. Resenhas de livros recentes deverão ter até 1.000 palavras. No caso de resenha crítica a algum artigo, o autor do texto criticado será informado e terá o mesmo espaço para réplica.

5. Comunicações são pequenos ensaios comentando atualidades relevantes, informando resultados parciais de pesquisa ou aplicando pontualmente um modelo teórico, e devem ter até 2.000 palavras.

6. Os trabalhos são submetidos à apreciação de pareceristas especialistas, preservando-se o anonimato das partes (double blind review).

7. O Comitê Editorial da Revista de Economia, de acordo com seus interesses editoriais, se reserva o direito de aceitar trabalhos em exceção às normas.

\section{REVISTA DE ECONOMIA}

Universidade Federal do Paraná - Departamento de Economia http://www.ser.ufpr.br/economia Av. Prefeito Lothário Meissner, 634, $1^{\circ}$. andar 80210-170 - Jardim Botânico, Curitiba - PR 


\section{NotAS AOS AUTORES SOBRE A FORMATAÇÃo DO TEXTO}

\section{Referências}

Deve-se utilizar o sistema de referências de Harvard. No texto, o sistema de Harvard usa uma referência abreviada com o nome do autor, ano de publicação do trabalho e, em caso de citação, o número da página do texto citado, como nos exemplos abaixo:

Conclui-se que "O período central de estatização da dívida externa é, portanto, o referente ao II PND, que tem como protagonistas a empresa estatal e as inversões em infra-estrutura" (Carneiro 1991:117).

O argumento encontra apoio em diversos outros autores (Alves 1999; Sá \& Rizzi 2001; Silva et al. 2004).

A expressão et al. deve ser usada no corpo do texto quando há três ou mais autores. Todos os autores devem ser apresentados na lista de referências ao fim do artigo.

Citações com mais de três linhas de extensão devem seguir tabulação especial, com espaçamento simples, como abaixo:

De acordo com Magalhães Filho (2002:208):

O apogeu da economia ervateira no Brasil dar-se-ia na década de 1920. Mas seria um apogeu com morte anunciada, posto que, desde a primeira década do século, a Argentina adotara políticas de fomento ao cultivo do mate (em Misiones) e de apoio à produção de erva-mate beneficiada no próprio país.

A data citada deve ser a data de publicação da fonte citada. A data de publicação da versão original, da versão traduzida ou de uma nova edição pode também ser apresentada entre colchetes na referência completa ao fim do texto, como abaixo:

KEYNES, John M. (1993) [1936]. The general theory of employment, interest and money. In The collected writings of John Maynard Keynes, vol. VII. Londres: Macmillan.

Quando há mais de uma obra em um mesmo ano de um mesmo autor, a distinção deve ser feita com o uso adicional de letras, como em 2005a e 2005b.

A lista de referências ao fim do texto deve conter todos os trabalhos citados. Certifique-se de que as datas, a ortografia e os títulos usados no texto estejam de acordo com o conteúdo das referências completas. 
Oriente-se pelos seguintes exemplos:

\section{Livros/autoria múltipla}

NELSON, R. \& WINTER, S. (1982). An evolutionary theory of economic change. Cambridge (MA): Harvard University Press.

MAKI, U. \& GUSTAFSSON, B. \& KNUDSEN, C. (eds.). (1993). Rationality, institutions \& economic methodology. Londres: Routledge.

\section{Artigo em livro editado}

SHIMA, Walter T. (2006). "Economia de redes e inovação." In PELAEZ, V. \& SZMRECSÁNYI, T. (orgs.). Economia da inovação tecnológica. São Paulo: Hucitec, pp. 333-64.

\section{Artigo em revista acadêmica}

DYMSKI, Gary A. (2005). "Banking strategy and financial exclusion: tracing the pathways of globalization.” Revista de Economia 31(1):107-43.

\section{Texto não publicado}

MONASTERIO, Leonardo M. (2002). Capital social e a região sul do Rio Grande do Sul. Curitiba: tese de doutorado, Universidade Federal do Paraná, Programa de Pós-Graduação em Desenvolvimento Econômico.

\section{Texto eletrônico}

VERNENGO, Matias (2003). "Late globalization and maladjustment: the Brazilian reforms in retrospective." URL [On line]: http://www. ideanetwork.org. Acesso em: 7 de maio de 2006. 


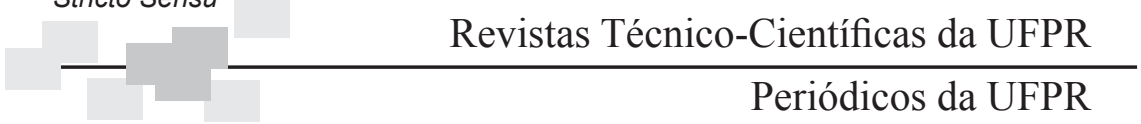

A Universidade Federal do Paraná instituiu o Sistema Eletrônico de Revistas (SER), abrindo um importante canal de interação entre usuários e a comunidade científica. Neste espaço estão listadas as Revistas Técnico-Científicas publicadas com recursos próprios ou com recursos do programa de apoio à publicação instituído pela UFPR.

O SER utiliza-se do Open Journal System, software livre e com protocolo internacional que permite a submissão de artigos e o acesso às revistas de qualquer parte do mundo. Nesse sistema já estão cadastradas 42 revistas da UFPR, abrangendo diversas áreas de conhecimento. O sistema pode ser acessado por AUTORES, para a submissão de trabalhos, CONSULTORES, para a avaliação dos trabalhos, EDITORES, para o gerenciamento do processo editorial e USUÁRIOS, interessados em acessar e obter CÓPIAS de artigos já publicados nas revistas.

A SUBMISSÃO de artigos é feita por meio eletrônico e o autor poderá fazer o ACOMPANHAMENTO do processo de AVALIAÇÃO por parte dos consultores até a editoração final do artigo. As NORMAS de publicação e demais instruções, bem como os endereços dos editores são encontrados nas páginas de cada revista.

O trabalho de editoração de algumas revistas (Boletim Paranaense de Geociencias, Desenvolvimento e Meio Ambiente, Educar em Revista, Extensão em Foco, História: Questões \& Debates, RA'E GA: O Espaço Geográfico em Análise, Revista de Economia e Revista Letras) é supervisionado pela EDITORA UFPR, que conta com corpo editorial especializado que se ocupa da revisão final dos volumes de seus respectivos periódicos, dentro dos padrões estabelecidos pela Editora. Findo o processo de editoração, uma cópia (pdf) dos artigos é disponibilizada em meio digital, dentro do Sistema SER, enquanto outra segue para impressão nas gráficas determinadas para cada publicação.

Para submeter um trabalho pela primeira vez será, antes, necessário entrar em CADASTRO. Uma vez cadastrado, abre-se uma caixa de diálogo indicando os passos a serem seguidos para o processo de submissão do artigo. Desejando apenas consultar trabalhos já publicados, basta acessar ARQUIVOS e obter o artigo desejado. 
O SER oferece ainda o Public Knowledge Project, poderosa ferramenta de pesquisa, com acessibilidade global. Para fazer a busca por um tema de seu interesse utilizando essa ferramenta basta clicar em PKP e, em seguida, digitar uma palavra-chave na caixa de diálogo. Com isso você acessará artigos sobre o tema de seu interesse publicados em diversas partes do mundo.

Universidade Federal do Paraná

Pró-Reitoria de Pesquisa e Pós-Graduação (PRPPG)

Rua Dr. Faivre, 405, Ed. D. Pedro II, $1^{\circ}$ andar, Centro

80060-140 - Curitiba - Paraná - Brasil

Tel.: (41) 3360-5405/ Fax: (41) 3360-5113

prppg@ufpr.br

ser@ufpr.br 

sta $\downarrow$ obra $\downarrow$ foi $\bullet$ impressa $\downarrow$ na $\bullet$ Gráfica $\downarrow$ Progressiva Curitiba $\downarrow$ PR Brasil $\downarrow$ em $\downarrow$ dezembro $\downarrow$ de $\downarrow 2009 \downarrow$ para a $\downarrow$ Editora $\bullet$ Universidade $\bullet$ Federal $\bullet$ do $\bullet$ Paraná $\bullet$ 